\title{
Influence of dietary lipid sources on sensory characteristics of broiler meat
}

\author{
A. Hugo ${ }^{2}$, S.P. Els ${ }^{1}$, C. Bothma ${ }^{2}$, F.H. de Witt ${ }^{1 \#}$, H.J. van der Merwe ${ }^{1}$ and M.D. Fair ${ }^{1}$ \\ ${ }^{1}$ Department of Animal, Wildlife and Grassland Science \\ ${ }^{2}$ Department of Microbial, Biochemical and Food Biotechnology \\ P.O. Box 339, University of the Free State, Bloemfontein 9300, South Africa
}

\begin{abstract}
A study was conducted to determine the influence of different dietary lipid sources and inclusion levels on sensory characteristics of chicken breast meat. Eight isoenergetic (15.1 MJ AME/kg DM) and isonitrogenous (223 g CP/kg DM) diets were formulated, using high oleic sunflower oil (HOSO), sunflower oil (SO), fish oil (FO) and tallow (T) at $30 \mathrm{~g} / \mathrm{kg}$ and $60 \mathrm{~g} / \mathrm{kg}$ inclusion levels. Eight hundred, day-old Ross 788 broiler males were randomly allocated to the eight treatments $(n=100)$ and further subdivided into four replicates/treatment $(n=25)$. All birds receive a commercial starter diet for the first 14 days, where-after the experimental diets were fed for 28 days. At 42 days of age, three birds/replicate ( $n=12 /$ treatment) were randomly selected, weighed and slaughtered at a commercial abattoir. Breast muscles were removed from the chilled carcasses $\left(4^{\circ} \mathrm{C}\right)$ and de-skinned. Meat samples were wrapped in aluminium foil and steamed (200 $\left.{ }^{\circ} \mathrm{C}\right)$ before cutting into smaller pieces $\left(2.5 \mathrm{~cm}^{3}\right)$ and served to the respondents $(\mathrm{n}=75)$ of a consumer panel. Each respondent tasted eight meat samples while completing a nine-point hedonic scale questionnaire. Meat samples of the HOSO treatment were preferred, while FO samples were the least acceptable to the respondents. These results suggested that dietary lipid sources could be used to manipulate sensory characteristics of broiler breast meat according to consumer preferences.
\end{abstract}

Keywords: Chicken breast, oil types, sensory properties, omega-3, 6 \& 9

${ }^{\#}$ Corresponding author: E-mail: dewittfh.sci@ufs.ac.za

\section{Introduction}

The important role of omega-3 (n-3) fatty acids in the prevention of cardiovascular diseases in humans is indispensable and the ideal omega-3 (n-3) to omega-6 (n-6) ratio to limit the negative effects of cardiovascular diseases is 4:1 (Gonzalez-Esquerra \& Leeson, 2000a). Nutritionists are able to manipulate the fatty acid profile of poultry products such as eggs and meat by means of dietary inclusion of lipid sources with the ideal fatty acid composition (Lopez-Ferrer et al. 2001). Various authors (Zollitsch et al., 1997; Crespo \& Esteve-Garcia, 2001; Villaverde et al., 2004) reported that the degree of unsaturation of the lipid source used during dietary manipulation also has a significant positive effect on production performance and carcass composition.

After appearance and tenderness, flavour is the most important characteristic of meat quality perceived by the consumer (Love, 1994). The development of the aroma and flavour of cooked meat is a very complex process in which different components react to produce chemical intermediates or final flavour volatiles (Campo et al., 2003). Production methods, rearing systems and nutritional parameters all have a significant influence on sensory quality attributes (Azcona et al., 2008).

Different studies have also focused on the role of fatty acids in meat flavour formation, since thermal lipid degradation is a major contributor to aroma volatiles (Mottram, 1991). Cameron \& Enser (1991) demonstrated that eating quality traits (tenderness, juiciness, flavour and overall acceptability) of pork were generally improved as the concentration of monounsaturated fatty acids (oleic acid) increased and polyunsaturated fatty acids (linoleic acid) decreased. The study by Cameron \& Enser (1991) also showed that higher concentrations of saturated and monounsaturated fatty acids were associated with higher taste panel scores, and that correlations between fatty acids and flavour were generally larger in magnitude than the correlations involving tenderness. It was also demonstrated that sensory quality may be adversely influenced by supplementation with fish oil or other omega-3 (n-3) polyunsaturated fatty acid (PUFA) sources such as linseed (Gonzalez-Esquerra \& Leeson, 2000a; b; Surai \& Sparks, 2001). Despite this the perception of fishy off-odour changes from one country to another, showing in some cases contradictory 
results (Azcona et al., 2008). While some authors obtained significant differences with $1.5 \%$ fish oil or linseed diet supplementation (Surai \& Sparks, 2001), other authors did not find significant differences up to 4\% fish oil supplementation (Lopez-Ferrer et al., 2001) indicating the differences in sensory perceptions of various respondents in different countries.

The aim of this study was to determine the effect of different dietary lipid sources (tallow, sunflower oil, high oleic sunflower oil and fish oil) and inclusion levels on sensory acceptability of broiler breast meat.

\section{Materials and Methods}

Eight hundred, day-old Ross 788 broiler males were randomly allocated to eight dietary treatments ( $n=100 /$ treatment). Each treatment was further subdivided into four replicates (25 birds/replicate). Birds receive a commercial starter diet for the first 14 days, whereafter the experimental diets were fed for 28 days. Eight isoenergetic (15.1 MJ AME/kg DM) and isonitrogenous (223 g CP/kg DM) diets were formulated, using high oleic sunflower oil (HOSO), sunflower oil (SO), fish oil (FO) and tallow (T) at $30.0 \mathrm{~g} / \mathrm{kg}$ and 60.0 $\mathrm{g} / \mathrm{kg}$ dietary inclusion levels. At 42 days of age, three birds/replicate ( $\mathrm{n}=12 /$ treatment) were randomly selected, weighed, marked and slaughtered at a commercial abattoir. Breast muscles were removed from the chilled carcasses $\left(4^{\circ} \mathrm{C}\right)$, de-skinned and stored $\left(-18{ }^{\circ} \mathrm{C}\right)$ for 14 days before determination of sensory characteristics.

All meat samples ( $n=12 /$ treatment) were coded with randomized 3-digit codes and rotated to prevent bias. Meat samples were lightly-salted and steamed $\left(200^{\circ} \mathrm{C}\right)$ in an oven, until a constant internal temperature of $90{ }^{\circ} \mathrm{C}$ was reached. The cooked breasts were cut into smaller cubes of $2.5 \times 2.5 \times 2.5 \mathrm{~cm}$ to serve to the respondents. Each sample was served in a $30 \mathrm{~mL}$ glass bowl, covered with a square of heavy-duty aluminium foil and served at an internal meat temperature of $60-65^{\circ} \mathrm{C}$. Seventy-five untrained respondents $(\mathrm{n}=75)$ participated in the consumer acceptance evaluation of the breast meat samples. Tasting of meat samples was performed at room temperature $\left(20-22^{\circ} \mathrm{C}\right)$ in individual testing booths under red light and each respondent tasted eight samples before completing the relevant questionnaire. Tap water at room temperature was provided for rinsing between samples during the taste sessions.

The questionnaire consisted of a nine-point hedonic scale (Lawless \& Heyman, 1998; Stone \& Sidel, 2004) where the respondents were to respond to the question of "how much do you like or dislike the sample?” The following scale was used to categorized the respondents' responses: one - dislike extremely, two - dislike very much, three - dislike moderately, four - dislike slightly, five - neither like nor dislike, six - like slightly, seven - like moderately, eight - like very much, nine - like extremely. Data were subjected to analysis of variance (ANOVA) and significant differences were identified by means of Tukey's (HSD) test (SAS, 1999).

\section{Results and Discussion}

The effect of different dietary lipid sources and inclusion levels on the respondents $(n=75)$ preferences of chicken breast meat are indicated in Table 1. From Table 1 it is evident that the preference for chicken meat samples originating from different dietary oil treatments differed significantly $(\mathrm{P}<0.0001)$. The most preferred chicken meat sample was from birds receiving the diet containing $60 \mathrm{~g} / \mathrm{kg}$ high oleic sunflower oil (HOSO 60). The average sensory score for this treatment was 6.60, which corresponds to the categories of "like slightly" and "like moderately" on the nine-point hedonic scale. These results on chicken meat samples, confirmed the findings of Cameron \& Enser (1991) who demonstrated that the eating quality traits of pork were generally improved as the concentration of monounsaturated fatty acids increased and polyunsaturated fatty acids decreased within the diet and/or the meat samples.

Chicken meat samples of the fish oil treatments were the least acceptable to the consumer panel with mean values of 4.29 - 4.47, which are categorized between "dislike slightly" and "neither like nor dislike" on the nine-point hedonic scale. These two samples originated from birds receiving respectively 30 and 60 $\mathrm{g} / \mathrm{kg}$ fish oil in their diets. This is in agreement with the findings of Gonzalez-Esquerra \& Leeson (2000a; b) and Surai \& Sparks (2001) who demonstrated that sensory quality of poultry meat may be adversely influenced by dietary supplementation with fish oil. This experiment also demonstrated that the South African consumer is sensitive to a fishy off-odour because the consumer panel could pick it up in the meat at dietary inclusion levels of $30 \mathrm{~g} / \mathrm{kg}$. It also seems that the sensory panel could not differentiate between chicken breast meat from birds receiving tallow and normal sunflower oil diets. 
Table 1 The effect (Mean \pm s.e.) of different dietary lipid sources and inclusion levels (30 and $60 \mathrm{~g} / \mathrm{kg}$ ) on the respondents $(n=75)$ preferences of chicken breast meat

\begin{tabular}{cc}
\hline Dietary lipid treatment & Mean \pm s.e. \\
\hline Fish oil $(30 \mathrm{~g} / \mathrm{kg})$ & $4.29^{\mathrm{d}} \pm 0.24$ \\
Fish oil $(60 \mathrm{~g} / \mathrm{kg})$ & $4.47^{\mathrm{d}} \pm 0.27$ \\
Tallow $(60 \mathrm{~g} / \mathrm{kg})$ & $5.37^{\mathrm{c}} \pm 0.22$ \\
Tallow $(30 \mathrm{~g} / \mathrm{kg})$ & $5.75^{\mathrm{bc}} \pm 0.19$ \\
High oleic sunflower oil $(30 \mathrm{~g} / \mathrm{kg})$ & $5.83^{\mathrm{bc}} \pm 0.19$ \\
Sunflower oil $(30 \mathrm{~g} / \mathrm{kg})$ & $5.96^{\mathrm{bc}} \pm 0.20$ \\
Sunflower oil $(60 \mathrm{~g} / \mathrm{kg})$ & $6.22^{\mathrm{ab}} \pm 0.18$ \\
High oleic sunflower oil (60 g/kg) & $6.60^{\mathrm{a}} \pm 0.18$ \\
$\mathrm{P}$ & $<0.0001$
\end{tabular}

a,b,c, d Treatment means with different superscripts within the column differ significantly (P <0.0001).

The frequency of the respondents' ratings per treatment on the nine-point hedonic scale regarding the "like" or "dislike" of broiler meat samples is graphically illustrated in Figure 1. Figure 1 can be divided into two parts: i.) bars pointing upwards, indicating the positive or "like" side of the hedonic scale, ranging from

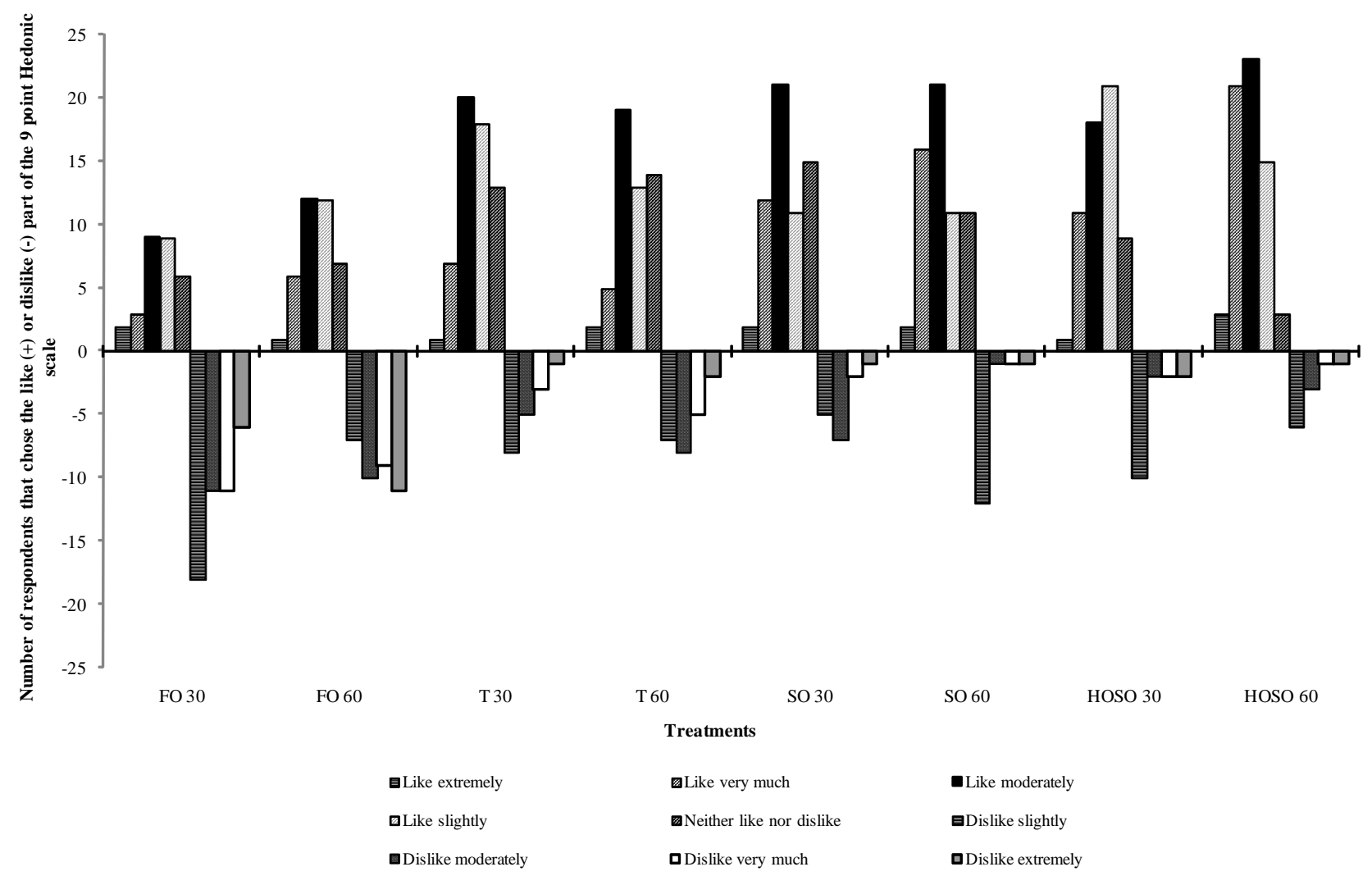

Figure 1 Frequency of respondent's ratings per treatment on the nine-point hedonic scale. Dietary treatments: HOSO 30 - High oleic sunflower oil (30 g/kg), HOSO 60 - High oleic sunflower oil (60 g/kg), SO 30 - Sunflower oil (30 g/kg), SO 60 - Sunflower oil (60 g/kg), FO 30 - Fish oil (30 g/kg), FO 60 - Fish oil (60 g/kg), T 30 - Tallow (30 g/kg) and T 60 - Tallow (60 g/kg) 
"like extremely" to "neither like nor dislike"; and ii) bars pointing downwards, indication the negative side of the hedonic scale, categorized as between "dislike slightly" to "dislike extremely". Although a very small part of the scale was used $(4.29-6.60)$, it is clear that the positive indicators were in general used more frequently than the negative ones. Even the response of respondents regarding breast meat samples from birds receiving tallow and sunflower oil was positive, with scores around six ("like slightly"). Meat samples of the FO 30 and FO 60 treatments, each containing 30 and $60 \mathrm{~g} / \mathrm{kg}$ fish oil, provoked the most negative responses by the respondents.

\section{Conclusions}

It is possible to improve the health properties of chicken by the inclusion of omega-9 (high oleic sunflower oil) or omega-3 (fish oil) in poultry diets. However, this is going to have implications on the sensory properties of the poultry products produced. Results from the present study indicate that dietary inclusion of high oleic sunflower oil was the most preferred ("most liked") by the respondents, while the inclusion of fish oil was the least preferred ("most disliked"), irrespective of dietary inclusion level. These results suggested that dietary lipid sources could be used to manipulate the sensory characteristics of broiler breast meat according to consumer preferences.

\section{References}

Azcona, J.O., Garcia, P.T., Cossu, M.E., Iglesias, B.F., Picallo, A., Perez, C., Gallinger, C.I., Schang, M.J. \& Canet, Z.E., 2008. Meat quality of Argintinean "Camperos" chicken enhanced in omega-3 and omega9 fatty acids. Meat Sci. 79, 437-443.

Cameron, N.D. \& Enser, M.B., 1991. Fatty acid composition of lipid in Longissimus Dorsi muscle of Duroc and British Landrace pigs and its relationship with eating quality. Meat Sci. 29, 295-307.

Campo, M.M., Nute, G.R., Wood, J.D., Elmore, S.J., Mottram, D.S. \& Enser, M., 2003. Modelling the effect of fatty acids in odour development of cooked meat in vitro: part I - sensory perseption. Meat Sci. 63, 367-375.

Crespo, N. \& Esteve-Garcia, E., 2001. Dietary fatty acid profile modifies abdominal fat deposition in broiler chickens. Poult. Sci. 80, 71-78.

Gonzalez-Esquerra, R. \& Leeson, S., 2000a. Alternatives for enrichment of eggs and chicken meat with omega-3 fatty acids. Can. J. Anim. Sci., 81, 295-305.

Gonzalez-Esquerra, R. \& Leeson, S., 2000b. Affects of menhaden oil and flaxseed in broiler diets on sensory quality and lipid composition of poultry meat. Br. Poult. Sci. 41, 481-488.

Lawless, H.T. \& Heymann, H., 1998. Sensory Evaluation of Food: Principles and Practices. (2 ${ }^{\text {nd }}$ Ed.). Chapman \& Hall, New York, U.S.A.

Lopez-Ferrer, M., Baucells, M.D., Barroeta, A.C. \& Grashornt, M.A., 2001. N-3 Enrichment of chicken meat. 1. Use of very long-chain fatty acids in chicken diets and their influence on meat quality: Fish oil. Poult. Sci. 80, 741-752.

Love, J., 1994. Product acceptability evaluation. In: Quality attributes and their measurement in meat, poultry and fish products. Eds Pearson, A.M. \& Dutson, T.R., Blackie Academic \& Professional, Glasgow, U.K.

Mottram, D.S., 1991. Meat. In: Volatile compounds in food and beverages. Ed. Maarse, H., Marcel Dekker. New York, U.S.A.

SAS, 1999. SAS ${ }^{\circledR}$ Users guide. Version 6.12. SAS Insitute Inc. Carey, N.C., USA.

Stone, H. \& SIDEL, J.L., 2004. Sensory Evaluation Practices. ( $3^{\text {rd }}$ ed.). Elsevier Academic Press, London.

Surai, P.F. \& Sparks, N.H.C., 2001. Designer eggs: From improvement of egg composition to functional food. Trends Food Sci. Technol. 12, 7-16.

Villaverde, C., Cortinas, L., Barroeta, A.C., Martín-Orúe S.M. \& Baucells, M.D., 2004. Relationship between dietary unsatturation and Vitamin E in poultry. J. Anim. Physiol. Anim. Nutr. 88, 143-149.

Zollitsch, W., Knaus, W., Aichinger, F. \& Lettner, F., 1997. Effects of different dietary fat sources on performance and carcass characteristics of broilers. Anim. Food. Sci. Technol. 66, 63-73. 